Delft University of Technology works at new ground-breaking insights and solutions to urgent societal problems in the world. Thanks to her faculties and unique large-scale technological research facilities, this university offers world-level multidisciplinary research and education.

The Department of Materials Science and Engineering seeks a motivated candidate of high academic quality to strengthen the department's research activities in the field of Metals for Extreme Conditions and to contribute to the educational programme at the graduate and post-graduate level. The new chair will address microstructural requirements, microstructure properties and metal applications in harsh environmental conditions.

The new appointee to the chair of Metals for Extreme Conditions is expected to develop and undertake a research programme in one or more of the following themes: production innovation, applications-related aspects such as energy generation, deep sea exploration, explosive loading, nuclear irradiated materials, replacement of scarce elements in alloy property design or other relevant subjects. The specific focus of the research within these fields will depend upon the expertise and interest of the appointee. It is expected that the appointee will develop activities in both experimental and theoretical aspects of materials science.

\section{Full Professor
Conditions}

Faculty/department

Level

Hours

Contract

Salary
Mechanical, Maritime and Materials Engineering

PhD degree Maximum of 38 hours per week (1 FTE) Tenured $€ 4904$ to $€ 8622$ per month gross

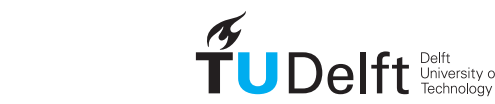

\title{
Challenge the future
}

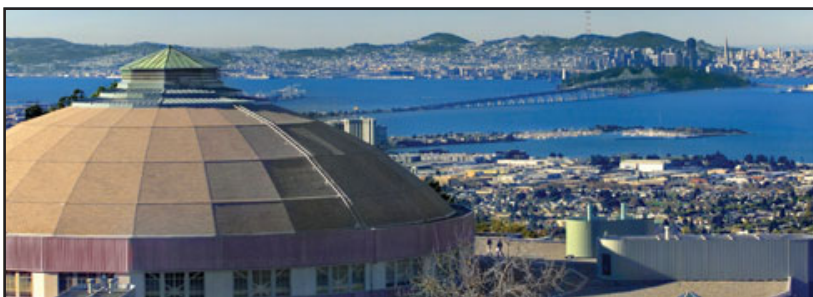

Lawrence Berkeley National Laboratory (Berkeley Lab) is located in the San Francisco Bay Area on a 200-acre site in the hills above the University of California's Berkeley campus and is managed by the University of California for the U.S. Department of Energy. A leader in science and engineering research for 75 years, Berkeley Lab is the oldest of the U.S. Department of Energy's national laboratories.

The mission of Berkeley Lab's Environmental Energy Technologies Division is to perform analysis, research, and development leading to better energy technologies and reduction of adverse energy-related environmental impacts.

EETD carries out its work through the support of the U.S. Department of Energy (the Division's primary sponsor), other federal entities, state governments and the private sector. Our staff of 500 represents a diverse cross section of fields and skills, ranging from architecture, physics, and mechanical engineering to economics and public policy.

Berkeley Lab's Environmental Energy Tech Department has several positions available at the Research/Staff Scientist/Scientist levels:

Fuel Cell Scientist (\#75615)

Battery Scientist (\#75590)

For detailed position descriptions and instructions regarding how to apply, please visit http://jobs.lbl.gov

Reference Job Number 75615 (Fuel Cell Scientist) or 75590 (Battery Scientist)

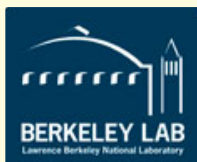

Berkeley Lab is an affirmative action/equal opportunity employer committed to the development of a diverse workforce.

\section{Sandia National Laboratories}

\section{R\&D, S\&E Materials Science, Staff Researcher}

Sandia National Laboratories is searching for a Materials Science Staff Researcher for the Nanoscale Sciences Department located in Albuquerque, NM. This position will require the ability to obtain and maintain a DOE-granted "Q-level" security clearance. Security clearance is not required to start.

The Nanoscale Sciences Department has a staff position available for leading-edge experimental materials scientist who can provide research leadership in nanoporous materials development (especially related to novel metal-organic frameworks materials synthesis and characterization) and asymmetric nanoparticle synthesis and functionalization (especially related to ferroelectric and dielectric platelet and rod materials) relevant for Department research thrust needs. We are seeking a highlyinnovative, adaptive and self-motivated nanostructured materials researcher who can develop a compatible research vision and flourish in a dynamic multidisciplinary team environment towards creating solutions that address challenging US Energy and National Security needs.

Requirements

A Ph.D. degree ( $>5$ years) in Materials Science, Chemistry, Chemical Engineering or related discipline; At least three professional references; The ability to effectively communicate their results in publications and presentations; Effective communication and interpersonal skills that foster effective scientific collaborations with a diverse population of researchers.

To learn more about additional requirements for this position and to apply online, please visit our Careers website at http://www.sandia.gov/careers/searchopenings.html, click Advanced Search and reference Job Opening ID Number: 643038

U.S. Citizenship Normally Required.

Equal Opportunity Employer. $M / F / D / N$

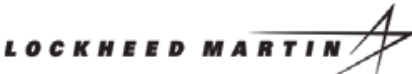




\section{TENURE-TRACK FACULTY POSITIONS}

\section{College of Engineering and Applied Sciences}

The College of Engineering and Applied Sciences invites applications for tenure-track faculty positions at the associate and full professor levels for the Department of Materials Sciences and Engineering and the Department of Energy Science and Engineering. Specific areas of interest include:

1. Informational materials: optoelectronic and non-linear optical materials, semiconductor materials, etc.;

2. Energy materials: energy-storing materials, photovoltaic cells, etc.;

3. Biomaterials and medical devices, microfluids, tissue engineering, cancer therapy, molecular electronics;

4. Material engineering: crystal growing, interface structure and properties, thin films, electronic materials;

5. Computational materials science.

Special requirements include highspeed, lowpower digital and mixed signal VLSI circuits; modern CMOS technology or MEMS technology; organic optoelectronic materials; and thin film fabricationMBE/MOCVD/sputtering

The College also invites applications for tenure-track faculty positions in materials science and engineering, quantum electronics and optical engineering, biomedical engineering, energy science and engineering, as well as interdisciplinary research areas.

Applicants must have earned their PhD or Master's degree in materials science and engineering or a related field, preferably with postdoctoral research experience. The successful candidates will be expected to conduct independent academic research, obtain external funding, and engage in teaching and public service duties.

Personal and working conditions: Start-up funds of 2 to 5 million RMB; annual salary of 160 to $400 \mathrm{k}$ RMB.

For more information, please visit http://eng.nju.edu.cn/index.php/en/jobs.

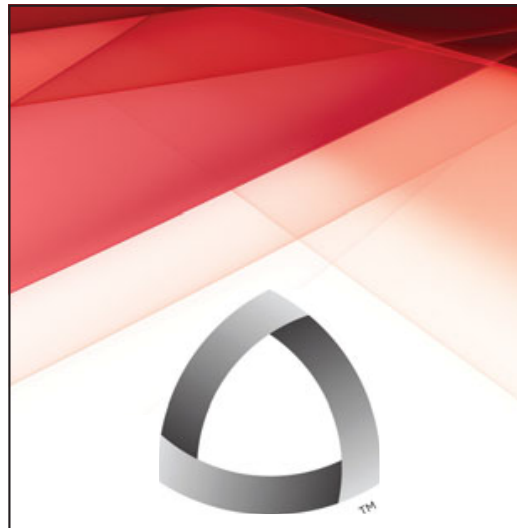

Colorado School of Mines

\section{J.H. Moore \\ Distinguished Professor}

The George S. Ansell Department of Metallurgical and Materials Engineering invites applications and nominations for the John Henry Moore Distinguished Professor of Metallurgical and Materials Engineering.

It is expected that the J.H. Moore Distinguished Professor will be a senior professor engaged and committed to the success of Metallurgical and Materials Engineering. Applicants must possess a PhD degree in Metallurgical Engineering, Materials Science and Engineering, or a closely related field. The successful candidate must have a documented and distinguished international record of scholarship, as well as documented ability in providing high quality education in materials science and engineering. A strong commitment to enhance student learning in the area of metallurgical and materials engineering, at both the undergraduate and graduate level, is required. Applicants must demonstrate excellent communication, organization, and interpersonal skills. Mines encourages applications from qualified candidates who can contribute to the diversity and excellence of our academic community through their research, teaching, and service.

For the complete job announcement and directions on how to apply, visit http:// inside.mines.edu/HR-AcademicFaculty.

Mines is an EEO/AA employer. School of Engineering and Applied Science, 3111 Engineering V, UCLA, 405 Hilgard Avenue, Los Angeles, CA 90095.

UCLA is an Equal Opportunity/Affirmative Action Employer and invites applications from women, minorities, and people with disabilities. 


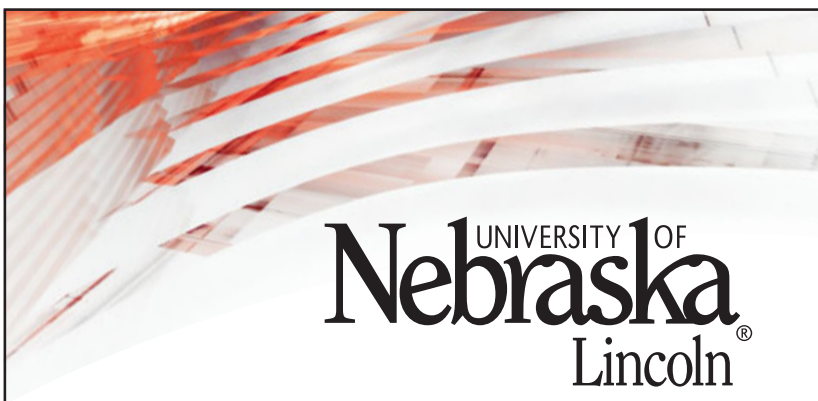

FACULTY POSITIONS

\section{Nanoscale Materials}

The Departments of Mechanical \& Materials Engineering and Electrical Engineering at the University of NebraskaLincoln (http://www.unl.edu) are seeking applicants for two positions in the general area of materials for energy, particularly nanoscale materials. Preference will be given to candidates at the full professor level, although outstanding candidates at the associate professor rank are encouraged to apply. Exceptional candidates will be considered for chaired professorships.

Applicants should have strong scholarly achievements and $\mathrm{PhD}$ degree or equivalent in materials science and engineering, electrical engineering, physics, or a closely related field. Successful candidates will have demonstrated success in establishing independent research programs, including a strong record of research support and scholarly activity. Candidates are also expected to have a strong commitment to excellence in education at both the undergraduate and graduate levels. Strong preference will be given to candidates whose research will build on existing strengths within the materials community at UNL, including the NSF-funded Materials Research Science and Engineering Center focused on nanomagnetism (www.unl.edu/mrsec), the Center for Nanohybrid Functional Materials (cnfm.unl.edu), and the Nebraska Center for Materials and Nanoscience (NCMN) (www.unl.edu/ncmn). The NCMN involves over 75 faculty across eight departments, and is headquartered in the new Voelte-Keegan Nanoscience Research Center, which houses an array of central facilities and space for collaborative projects.

Applications (including CV, detailed research and teaching statements, and names of three references) should be submitted as one pdf-formatted document on-line at http://employment.unl.edu. Applications will be accepted until the positions are filled. Tenure home will be based on the successful applicants' strengths and background.

The University of Nebraska has an active National Science Foundation ADVANCE gender equity program, and is committed to a pluralistic campus community through affirmative action, equal opportunity, worklife balance, and dual careers.

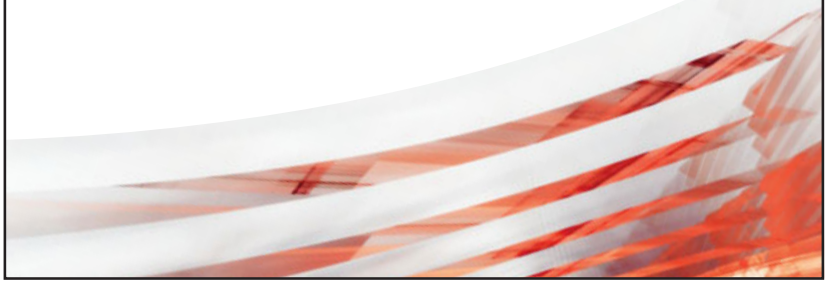

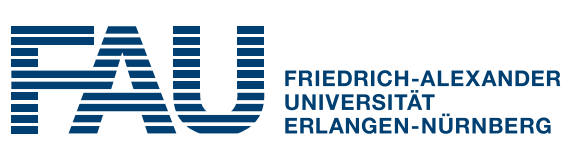

The Cluster of Excellence 'Engineering of Advanced Materials - Hierarchical Structure Formation of Functional Devices' (EAM, www.eam.fau.de), funded by the German Research Foundation (DFG), at Friedrich-AlexanderUniversität Erlangen-Nürnberg (FAU), Germany, invites applications for a permanent

\section{W2-Professorship for Materials Science (Thin Film Formation)}

The successful candidate should have excellent research qualifications in the area of thin film deposition and microstructure formation from the liquid phase, as well as in the characterisation, analysis and modeling of thin film formation. Applicants are expected to have experience in interdisciplinary research and the necessary skills to develop an internationally recognised fundamental research programme in close collaboration with the Cluster's other research areas. She or he will be expected to play an active role in the EAM Focal Topic 'Self-organization \& processing of thin films from liquids', one of the Cluster's research platforms. Access to the various printing and coating facilities at Friedrich-Alexander-Universität Erlangen-Nürnberg and the Bavarian Center of Applied Energy Research (ZAE Bayern) will be provided.

The position also includes teaching duties in the curricula of the Department of Materials Science and Engineering. The successful candidate will furthermore be expected to take on administrative duties and to raise external funding.

Required qualifications include university graduate and doctoral degrees, excellent teaching skills, and a Habilitation or equivalent qualification, which may have been gained outside the university or within a junior professorship.

The University of Erlangen-Nürnberg is committed to a profamily and equal opportunities policy and offers support for dual-career-couples. We strongly encourage women to apply in an effort to increase female representation in research and teaching.

Application documents (curriculum vitae, list of publications and teaching activities, copies of degree certificates but no publications) and a brief summary of research interests should be submitted by e-mail by April 28, 2013 at the latest to administration@eam.uni-erlangen.de, Cluster of Excellence Engineering of Advanced Materials, Prof. Dr. Christoph Brabec, Nägelsbachstraße 49b, D-91052 Erlangen.

www.fau.de
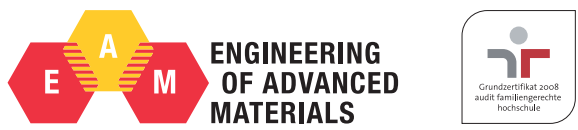


\section{Senior Positions-All Ranks NINGBO INSTITUTE OF MATERIAL TECHNOLOGY AND ENGINEERING (NIMTE) • CHINESE ACADEMY OF SCIENCES}

Ningbo Institute of Material Technology and Engineering (NIMTE) of Chinese Academy of Sciences (CAS) is located in Ningbo, a prosperous port city in Zhejiang Province of China that enjoys both a rich cultural heritage and highly developed economy. NIMTE is the first institute of CAS in Zhejiang Province. Founded in 2004 with the core value to "Facilitate the application of scientific research achievements, and deliver innovative solutions for industry and society," NIMTE has the vision to become a unique world-class research institute in materials science, technology, and engineering.

NIMTE is mainly engaged in the research on magnetic materials, polymer and composite materials, functional materials and nano-devices, surface engineering, and new energy materials. In March 2009, NIMTE launched the construction phase 2 to be upgraded to the Ningbo Industrial Technology Research Institutes (NITRI), consisting of three subsidiary institutes respectively named the Institute of Materials Technology, the Institute of Advanced Manufacturing, and the Institute of New Energy Technology.

NIMTE owns a public technical service platform with facilities valued at 250 million RMB. At present, NIMTE has 723 staff, including one academician and about 150 professors. NIMTE has undertaken more than 700 research projects with a total grant of 1000 million RMB. In the past few years, NIMTE has filed 647 patents and published over 660 scientific papers and proceedings. NIMTE focuses on the development of new materials, new energy, and advanced manufacturing techniques. The research information can be found at http://www.nimte.ac.cn/.

NIMTE invites outstanding applications in emerging fields for senior positions at all ranks, including the National "Full-time Qianren" candidate, the "Youth Qianren Talents," the "Hundred Talents Program" of CAS, the "Qianren" of Zhejiang, and the Flagship Leader, Team Leader, and Young Leader of NIMTE. Appointments can be at the Chief Professor/Engineer, full, or associate professor rank commensurate with the candidate's experience and accomplishments.

NIMTE offers generous and competitive start-up packages, including startup funds of 0.5-10 million RMB, house purchasing privilege and subsidies under the Talent Recruitment Programs, additional bonuses based on individual performance, and effective profit distribution.

Applications and nominations enclosing an updated $\mathrm{CV}$ should be sent to:

Dr. Ruili Zhang, Department of Human Resources

Ningbo Institute of Material Technology and Engineering

519 Zhuangshi Road, Zhenghai, Ningbo

Zhejiang, P. R. China 315201

Tel: (86) $574-87911123$

E-mail: rlzhang@nimte.ac.cn

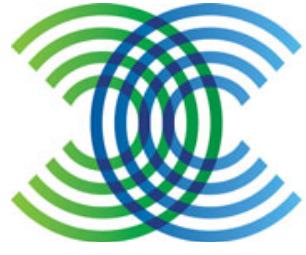

FRONTIER INSTITUTE

OF SCIENCE AND TECHNOLOGY 前沿科学技术研究院

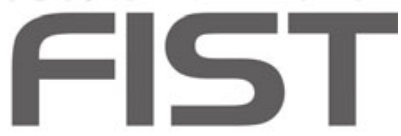

FIST is a large selective investment by XJTU in an effort to establish a world-class, multi-disciplinary research institute. To achieve this goal, FIST is setting up a number of research centers of excellence in Mathematics, Physics, Chemistry, Bio-Science/Life-Science/Basic-medical-Science, and Materials Science, and adopts a new management system similar to that of most U.S. universities. Ten planned centers have been established recently, and FIST is now recruiting the remaining Center Directors. In addition, FIST invites applications to fill its multiple, fulltime tenure-track faculty positions at all levels (from lab director to group leader), as well as postdoctoral positions. See our Chinese ad at http://fist.xjtu.edu.cn/zp.php?id=5 for details.

An eligible candidate for the Center Director position should be an internationally renowned scientist and established leader in his/her field, with the ability and will to build his/her center into an internationally recognized center of excellence. Successful candidates will be provided with a sizable start-up package to establish a research center, together with a highly competitive salary. See our Chinese ad at http://fist.xjtu.edu.cn/zp.php?id=5 for details.

In addition to the Center Director positions, FIST also invites applications in the above-mentioned areas to fill its tenure-track faculty positions at all levels, from lab director to group leader. Applications for postdoctoral positions are also welcome. An eligible faculty candidate should

\section{Center Directorships | Tenure-track Faculty Positions | Postdoctoral Research Fellows}

Frontier Institute of Science and Technology (FIST) Xi'an Jiaotong University (XJTU)

Valid through June 30, 2013

have a track-record for excellence in research and the potential to lead a lab or a group to success. Successful candidates will be provided with a competitive start-up package including salary, lab space, and start-up fund, together with other benefits. Position level and start-up package will vary with the candidate's qualification. See our Chinese ad at http://fist.xjtu. edu.cn/zp.php?id=5 for details.

Interested individuals should set up their free ResearcherID webpage on http://www. researcherid.com/. Please send your ResearcherlD citation information along with a cover letter, $\mathrm{CV}$, and a list of ten representative publications to:

Dr. Xiangli Meng

Frontier Institute of Science and Technology (FIST)

Xi'an Jiaotong University

1 West Building, 99 Yanxiang Road

Yanta District, Xi'an, Shaanxi Province

P.R.China 710054

Tel/Fax: +862983395131

Email: fist@mail.xjtu.edu.cn 